\title{
Oncogenes in Cell Survival and Cell Death
}

\author{
Jake Shortt ${ }^{1}$ and Ricky W. Johnstone ${ }^{1,2}$ \\ ${ }^{1}$ Cancer Therapeutics Program, Gene Regulation Laboratory, Peter MacCallum Cancer Centre, East Melbourne \\ 3002, Victoria, Australia \\ ${ }^{2}$ Department of Pathology, University of Melbourne, Parkville 3052, Victoria, Australia \\ Correspondence: ricky.johnstone@petermac.org
}

The transforming effects of proto-oncogenes such as MYC that mediate unrestrained cell proliferation are countered by "intrinsic tumor suppressor mechanisms" that most often trigger apoptosis. Therefore, cooperating genetic or epigenetic effects to suppress apoptosis (e.g., overexpression of BCL2) are required to enable the dual transforming processes of unbridled cell proliferation and robust suppression of apoptosis. Certain oncogenes such as $B C R-A B L$ are capable of concomitantly mediating the inhibition of apoptosis and driving cell proliferation and therefore are less reliant on cooperating lesions for transformation. Accordingly, direct targeting of BCR-ABL through agents such as imatinib have profound antitumor effects. Other oncoproteins such as MYC rely on the anti-apoptotic effects of cooperating oncoproteins such as BCL2 to facilitate tumorigenesis. In these circumstances, where the primary oncogenic driver (e.g., MYC) cannot yet be therapeutically targeted, inhibition of the activity of the cooperating antiapoptotic protein (e.g., BCL2) can be exploited for therapeutic benefit.

Prions roto oto-oncogenes perform physiological functions that are necessary for normal cellular homeostasis. In particular, proto-oncogenes govern the processes of growth, proliferation, and survival that a cancer cell can exploit to gain competitive advantages over its non-neoplastic counterparts (Hanahan and Weinberg 2011). During malignant transformation, an emerging clone must circumvent the antineoplastic countermeasures that usually regulate the activity of proto-oncogenes (Hanahan and Weinberg 2011). Tumor cells can then use the beneficial properties of an oncogene (e.g., enhanced proliferation) without the negative effects of "fail-safe" countermeasures that have been otherwise overridden (Lowe et al. 2004). Indeed "intrinsic tumor suppression" activities such as cellular senescence or apoptosis are triggered when a cell is driven to uncontrolled proliferation through the inappropriate activity of an oncogene (Lowe et al. 2004). One of the best examples of such a fail-safe mechanism is detailed later in this review through the focus on $c-M Y C$ that concomitantly induces cell proliferation and apoptosis. In this instance, cooperating lesions that inhibit apoptosis (e.g., loss of function of $\mathrm{p} 53$ or overexpression of BCL2) are required to facilitate $M Y C$-driven tumorigenesis (Fig. 1). In contrast, an oncogene such as BCL2 may have the capacity to inhibit apoptosis but

Editors: Eric H. Baehrecke, Douglas R. Green, Sally Kornbluth, and Guy S. Salvesen

Additional Perspectives on Cell Survival and Cell Death available at www.cshperspectives.org

Copyright (C) 2012 Cold Spring Harbor Laboratory Press; all rights reserved; doi: 10.1101/cshperspect.a009829

Cite this article as Cold Spring Harb Perspect Biol 2012;4:a009829 
J. Shortt and R.W. Johnstone
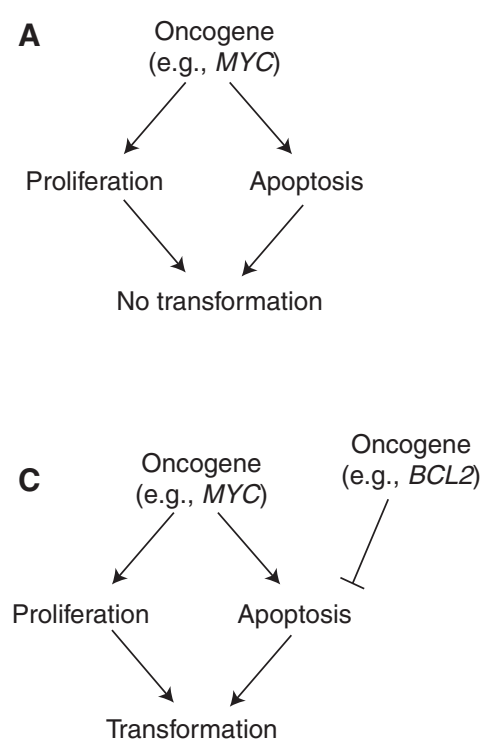

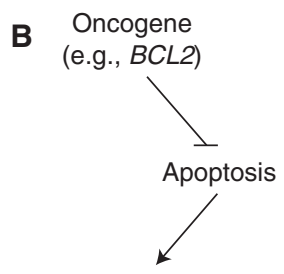

No transformation

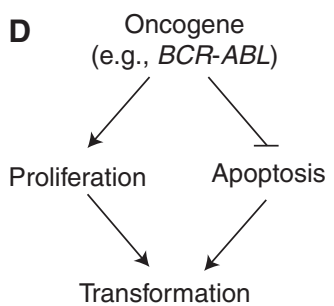

Figure 1. Cellular transformation through concomitant stimulation of cell proliferation and inhibition of apoptosis. (A) Oncogenes such as MYC induce cellular proliferation, however, intrinsic "fail-safe" apoptotic mechanisms such as those induced by the ARF/MDM2/P53 pathway counteract the mitotic stimulus mediated by MYC and suppress transformation. (B) Oncogenes such as BCL2 are potent inhibitors of apoptosis but poor inducers of cell proliferation and are, therefore, insufficient to drive tumorigenesis as a single oncogenic event. (C) The cooperative activity of oncogenes such as MYC and BCL2 suppress apoptosis and drive proliferation resulting in cellular transformation. $(D)$ Certain oncogenes such as $B C R-A B L$ can activate signaling pathways that simultaneously induce cell proliferation and suppress apoptosis, thereby leading to transformation.

does not contain strong intrinsic mitogenic activity and therefore cooperating oncogenes that drive cell proliferation (e.g., RAS, MYC) are required for cellular transformation (Strasser et al. 1990; Lee et al. 2007) (Fig. 1). Finally, there are oncoproteins that engage multiple signal transduction pathways (e.g., $B C R-A B L$ ) that can concomitantly activate both cell proliferation and cell survival (reviewed by Druker 2008). Such oncoproteins may therefore be less reliant on secondary genetic or epigenetic hits to initiate tumorigenesis (Fig. 1).

Oncogenes are identifiable by their capacity to transform a cell in the context of deregulated expression or function. Mechanisms of oncogene activation are diverse and include upregulated expression of a normal gene product, expression of mutant protein with enhanced stability or altered functionality or altered recruitment or subcellular localization of a normal gene product through interaction with an aberrantly expressed or mutant binding partner. Perhaps the simplest illustrations of deregulated oncogene expression in malignant transformation can be found in B-cell lymphomas. Here, as a lymphocyte undergoes genomic $\mathrm{V}(\mathrm{D}) \mathrm{J}$ rearrangement to generate antibody specificities, oncogenes may be switched on by "accidental" rearrangement alongside powerful immunoglobulin gene enhancer elements (Kuppers and Dalla-Favera 2001). The resulting "switch-translocations" define lymphomas at a chromosomal level, and strongly implicate the rearranged oncogenes as initiating lesions in lymphomagenesis (Table 1). Classical examples include immunoglobulin heavy chain $(I G H)$ $c M Y C$ translocations in Burkitt lymphoma and $I G H-B C L 2$ translocations in follicular lymphoma. MYC and BCL2 are considered prototypic oncogenes and their diverse mechanisms of transformation will be highlighted in this review. Neoplastic transformation is a multistep 
Oncogenes in Cell Survival and Cell Death

Table 1. Examples of oncogenes revealed by IGH-switch translocations

\begin{tabular}{|c|c|c|c|}
\hline Oncogene & Disease & Gene product (protein) function & Effects \\
\hline$B C L 2$ & Follicular lymphoma & $\begin{array}{l}\text { Prevents mitochondrial outer } \\
\text { membrane permeabilization }\end{array}$ & Antiapoptotic \\
\hline BCL6 & $\begin{array}{l}\text { Diffuse large B-cell } \\
\text { lymphoma }\end{array}$ & Transcription factor & Proliferative, differentiation block \\
\hline BCL10 & $\begin{array}{l}\text { Extranodal marginal } \\
\text { zone lymphoma }\end{array}$ & $\begin{array}{l}\text { Caspase-recruiting domain } \\
\text { containing protein }\end{array}$ & $\begin{array}{l}\text { Activation of prosurvival signaling } \\
\text { (e.g., NF-кB), proapoptotic }\end{array}$ \\
\hline CCND1 & $\begin{array}{l}\text { Mantle cell } \\
\text { lymphoma }\end{array}$ & $\begin{array}{l}\text { Activates cyclin dependent } \\
\text { kinases }\end{array}$ & Proliferative \\
\hline CDK6 & $\begin{array}{l}\text { Splenic marginal } \\
\text { zone lymphoma }\end{array}$ & Cyclin dependent kinase & Proliferative \\
\hline FGFR3 & Plasma cell myeloma & Receptor tyrosine kinase & $\begin{array}{l}\text { Proliferative, activation of prosurvival } \\
\text { signaling (e.g., PI3K, MAPK) }\end{array}$ \\
\hline$c M A F$ & Plasma cell myeloma & Transcription factor & $\begin{array}{l}\text { Proliferative, altered interactions with } \\
\text { tumor microenvironment }\end{array}$ \\
\hline MALT1 & $\begin{array}{l}\text { Extranodal marginal } \\
\text { zone lymphoma }\end{array}$ & Protease/paracaspase & $\begin{array}{l}\text { Activation of prosurvival signaling } \\
\quad(\text { e.g., NF-кB) }\end{array}$ \\
\hline$c M Y C$ & Burkitt lymphoma & Transcription factor & $\begin{array}{l}\text { Proliferative, proapoptotic, } \\
\text { prosenescent }\end{array}$ \\
\hline
\end{tabular}

process involving cooperating activation of oncogenes and/or silencing of tumor suppressors in order for a clone to achieve full malignant potential (Hanahan and Weinberg 2000). Accordingly, deregulation of a single oncogene is usually insufficient to transform a cell.

\section{INITIATING LESIONS AND THE CONCEPT OF "ONCOGENE ADDICTION"}

The genetic complexity of neoplastic transformation varies from tumor to tumor. Whereas lymphomas arising from $I G H$ switch translocations may be relatively monomorphic in their genetic make-up, carcinomas often have complex aneuploid DNA harboring multiple aberrancies (Kinzler and Vogelstein 1996, 1998). As such, the initial oncogenic event that spawned a genetically complex cancer can be difficult to determine. However, certain malignancies clearly evolve in a stepwise fashion that builds on an initiating oncogenic "hit." As this stepwise progression rests on the beneficial effects of a primary oncogene, the developing cancer becomes increasingly dependent on that oncogene for viability. At this point, the cancer is considered "oncogene-addicted" because of its heightened reliance on the offending gene products (Wein- stein 2002). Selective targeting of an oncogene of addiction is a major goal in cancer therapeutics, in which oncogene dependency represents a potential vulnerability in cancer cell survival (Weinstein 2002).

\section{MECHANISMS OF COOPERATIVE ONCOGENIC TRANSFORMATION}

Oncogenes show diversity in their proneoplastic effects and in the regulatory fail-safes that protect against transformation. Some oncogenes such as $B C R-A B L$ possess a near-complete repertoire of proneoplastic properties, requiring less assistance from cooperative mutations (reviewed by Perrotti et al. 2010). Other oncogenes have a narrow spectrum of biological activity (e.g., BCL2) or simultaneously trigger cell proliferation and cell death/senescence (e.g., $M Y C$ ) and therefore cannot transform a cell without cooperating lesions that blunt or inhibit the intrinsic tumor suppressor mechanisms. In this way, the disruption of a specific prosurvival effector can combine with broader oncogenic hits to potently accelerate the development of cancer. For example, deregulation of MYC drives cell growth and proliferation, but its net effect is countered by increased rates of 
apoptosis (Evan et al. 1992). If deregulated, $M y c$ activity is then combined with $B c l 2$ overexpression, the apoptotic fail-safe is removed in a synergistic route to transformation (Strasser et al. 1990) (Fig. 1). This paradigm is illustrated by the ability of MYC to cooperate with a range of antiapoptotic proteins in experimental models of lymphomagenesis (Beverly and Varmus 2009; Whitecross et al. 2009; Campbell et al. 2010). Moreover in the clinic, "double-hit" lymphomas containing MYC and BCL2 translocations are recognized as a distinct entity with poorer prognosis (Aukema et al. 2011).

\section{MYC-AN EXAMPLE OF A TWO-EDGED SWORD IN ONCOGENESIS}

Deregulation of MYC gene expression is one of the most frequently encountered events in human cancer, implicated in over half of all malignancies (reviewed by Vita and Henriksson 2006). Signal transduction pathways activated in response to nutrients, growth factors, and mitogenic stimuli relay signals from phosphorylation cascades directly to MYC. For example, ERK, the canonical downstream effector of the RAS/RAF/MEK/ERK pathway stabilizes MYC by phosphorylation of serine 62 (Sears 2004; Gustafson and Weiss 2010). Conversely, glycogen synthase kinase (GSK)-3 $\beta$ mediated phosphorylation of Myc at serine 58 has a destabilizing effect (Sears 2004). GSK-3 $\beta$ is antagonized by AKT, a nodal effector in the phosphotidylinositol-3-kinase (PI3K) pathway. Therefore, RAS/RAF and PI3K/AKT signaling cooperate to promote MYC protein stability in response to optimal growth conditions.

The MYC gene promoter receives input from many transcription factors and is normally switched on in response to mitogenic stimuli. In particular MYC is transactivated by E2F transcription factors released from $\mathrm{RB}$ in response to phosphorylation by cyclin/cyclin dependent kinase (CDK) complexes (Oswald et al. 1994). MYC gene-targets are implicated in most aspects of cellular physiology, however, those involved in growth and proliferation feature prominently. The proliferative effects of MYC are evident at multiple points in cell-cycle regulation. For ex- ample, MYC activates transcription of D-type cyclins and CDKs to promote cell cycle check point progression (Hermeking et al. 2000; Bouchard et al. 2001). At the same time, MYC represses the expression of CIP/KIP family cyclin/ CDK inhibitors (Seoane et al. 2002). To prepare the cell for division, MYC augments the processes of ribosomal biogenesis (Gomez-Roman et al. 2006) and $5^{\prime}$ cap-dependent translation (Lin et al. 2009), allowing a cell to manufacture protein and accumulate biomass. MYC also modulates specific metabolic pathways integral to cell growth, such as glucose and iron homeostasis (Adhikary and Eilers 2005).

Unbridled MYC activity is a potent oncogenic stimulus, requiring stringent regulation at every possible level from transcriptional control to protein stability. MYC also possesses inherent proapoptotic and prosenescent properties that must be overcome before neoplastic transformation can occur. As discussed in detail below, MYC activates p53-driven apoptosis programs through the ARF tumor suppressor protein (Lowe et al. 2004). These dual proneoplastic and cancer-protective properties make MYC a "two-edged sword" in oncogenesis.

\section{CANCER-PROTECTIVE PROPERTIES OF MYC}

\section{MYC-Induced Apoptosis}

MYC's inherent proapoptotic properties safeguard against malignant transformation. To a large extent, MYC's apoptotic activity is underpinned by its capacity to initiate a DNA-damage response (DDR) and activate the MDM2-ARFp53 tumor suppressor pathway (Lowe et al. 2004; Meyer and Penn 2008). Proposed mechanisms for DDR activation include generation of genotoxic reactive oxygen species and formation of aberrant DNA replication intermediates (Vafa et al. 2002). Upregulation of ARF in response to MYC stabilizes p53 expression by antagonism of MDM2. Augmented p53 activity counteracts the proliferative effects of MYC and activates p53dependent apoptotic effectors such as PUMA and Noxa. MYC also up-regulates the p53-independent expression of proapoptotic BIM ( $\mathrm{He}-$ mann et al. 2004). The importance of MYC's 
interaction with the DDR and apoptosis is highlighted in experimental models of MYC-transformation and human Burkitt lymphoma. Genetic interrogation of these cancers reveals the majority contain perturbations in the MDM2ARF-p53 pathway as a means to bypass MYCinduced apoptosis (Eischen et al. 1999). Accordingly, genetic crosses of $M y c$ transgenic mice with p53-, p19 Arf-, or Atm-deficient mice results in accelerated tumorigenesis by inhibition of $M y c$-induced apoptosis (Schmitt et al. 1999; Reimann et al. 2007). Moreover, knockdown or knockout of Puma (Hemann et al. 2004) and to a lesser extent Noxa (Michalak et al. 2009) also accelerates $M y c$-induced lymphomagenesis. Conversely, genetic manipulation to overexpress Bcl2 family proteins (Schmitt et al. 2002; Beverly and Varmus 2009; Whitecross et al. 2009; Campbell et al. 2010) or delete Bim (Egle et al. 2004) in preneoplastic $M y c$-overexpressing stem cells greatly enhances the oncogenic activity of $M y c$ and concomitantly relieves the pressure to mutate 553 or p 19 Arfin $M y c$-driven tumorigenesis. These data provide compelling evidence that suppression of $M y c$-induced apoptosis in the presence of a strong pro-proliferation signal by $M y c$ cooperate to drive tumorigenesis.

\section{ONCOGENIC SIGNAL TRANSDUCTION PATHWAYS AND REGULATION OF APOPTOSIS}

Diverse signal transduction pathways can be activated by upregulated expression of oncoproteins or gain-of-function mutations leading to abnormal protein activity. For example, gainof-function receptor mutations can initiate ligand-independent receptor tyrosine kinase (RTK) or G-protein coupled receptor (GPCR) activity. Similarly, activating mutations of RAS and PI3K can amplify the responses to upstream receptor ligation or cause ligand-independent pathway activation (Vivanco and Sawyers 2002; Engelman 2009). Moreover, chromosomal translocations can give rise to aberrant fusion proteins with oncogenic enzymatic activity (e.g., $B C R$ $A B L)$. A common feature of these oncogenic signaling molecules is their ability to simultaneously stimulate cellular proliferation and sup- press apoptosis. Although reductionist scientific approaches describe canonical linear signaling cascades, in reality complex networks of communicating proteins exist within a cell. Oncogenic activation of one prosurvival "pathway" can lead to compensatory downregulation of another. For this reason, a combination of upstream genetic lesions (e.g., mutation of PI3K and $R A S$ ) can cooperate by circumventing regulatory modulation by negative feedback loops between networks. It is now recognized that virtually all cancers show either activation of an oncogenic kinase and/or silencing of a tumorsuppressor phosphatase. Below we will provide examples of oncoproteins that either alone or in combination activate a diverse array of signaling pathways to provide the dual transforming effect of uncontrolled cell proliferation and inhibition of apoptosis.

\section{BCR-ABL AND THE CHRONIC MYELOPROLIFERATIVE NEOPLASMS}

The initiating lesion of CML arises by reciprocal translocation of $c$-ABL1 on chromosome 9 with the $B C R$ gene on chromosome 22 to generate the BCR-ABL fusion protein with greatly enhanced CABL-1 kinase activity. Acquisition of this $B C R-A B L$ fusion is sufficient to transform hematopoietic stem cells (Kharas et al. 2008; Perrotti et al. 2010). The effects of constitutive BCR-ABL activity are pleiotropic and include enhanced cellular proliferation, evasion of apoptosis, and increased capacity for cell self-renewal (Druker 2008). Enhanced proliferation and survival are variably attributable to concomitant and coordinated activation of PI3K, JAK/STAT, and RAS/RAF/MEK/ERK pathways (Druker 2008). At the same time, BCR$\mathrm{ABL}$ sets the scene for acquisition of new oncogenic lesions by promoting genomic instability and downregulating tumor suppressors (Nowicki et al. 2004; Koptyra et al. 2008). Clonal evolution to blast crisis is most commonly accompanied by mutations of the MDM2ARF-p53 axis and transcription factors including RUNX1 and IKZF1 (Perrotti et al. 2010). Although these secondary lesions cluster within the terminal phenotypes of myeloid and 
lymphoid blast crises, they do not follow a consistent pattern between patients. Therefore, it appears deregulated BCR-ABL expression provides a "fertile soil" for further oncogenic devolution, and these secondary events occur stochastically and additively to convey a more aggressive phenotype.

\section{GROWTH-FACTOR RECEPTOR MUTATIONS IN EPITHELIAL CANCERS}

Deregulated expression or activity of members of the epidermal growth factor receptor (EGFR) family underlies development of a range of epithelial tumors across numerous tissues (Wheeler et al. 2010). These cell surface proteins function as RTKs, and EGFR (ERBB1/HER1) and HER2/NEU (ERBB2) are the most extensively studied members of the family. EGFR activation results in an explosion of intracellular signaling including triggering of the RAS/RAF / MEK/ERK and PI3K/AKT/MTOR pathways, as well as activation of Src tyrosine kinases, PLC $\gamma$, and STATs 3 and 5 (Marmor et al. 2004). The net result of simultaneous activation of these pathways is enhanced cellular proliferation, suppression of apoptosis, and cellular transformation that is conceptually and somewhat mechanistically similar to that described above for $B C R-A B L$ (Fig. 1).

\section{PI3K AND AKT}

PI3K is a lipid kinase that integrates afferent signals from GPCRs, RTKs, RAS, and other drivers of oncogenic signal transduction to activate downstream targets implicated in growth, proliferation, and evasion of apoptosis (reviewed by Engelman et al. 2006). As such, PI3K plays an important role in facilitating GPCR, RTK, and RAS-initiated oncogenesis. Indeed, pharmacological or genetic silencing of PI3K severely impairs the ability of $B C R-A B L$ to transform hematopoietic stem cells (Kharas et al. 2008) and induces apoptosis in epithelial tumors "addicted" to EGFR and HER2 (Faber et al. 2009). However, PI3K is much more than a passive yet important conduit in oncogenesis, as aberrant PI3K activation by mutation or gene amplifica- tion is observed in a range of solid-organ malignancies.

Within the PI3K family, class IA PI3K is the most closely associated with cancer. Class IA PI3K consists of a catalytic ( $\mathrm{p} 110)$ and regulatory (p85) subunit. There are four p110 isoforms $(\alpha, \beta, \gamma, \delta)$ encoded by the PIK3CA, PIK3CB, PIK3CG, and PIK3CD gene loci, respectively. The PIK3R1 gene encodes the $\mathrm{p} 85$ regulatory subunit that has a suppressive effect on p 110 catalytic activity that is relieved by an interaction with phosphorylated Tyr residues on RTKs. PIK3CA and PIK3R1 have been identified as oncogenes and somatic-activating mutations of PIK3CA occur in $30 \%$ of epithelial cancers and precursor lesions (reviewed by Engelman 2009). PIK3CA mutations increase lipid kinase activity in the absence of receptor activation, promoting cell transformation in vivo (Engelman 2009). The oncogenic activity of PI3K has largely been attributed to its ability to activate mammalian target of rapamycin complex (MTORC)-1 and AKT (Engelman 2009). MTORC-1 is considered a master controller of cell growth, as it modulates the processes of ribosomal biogenesis and $5^{\prime}$ cap-dependent translation (Schmelzle and Hall 2000).

AKT itself is an oncogene, first identified as the cellular homolog of a virally encoded protein (vAKT) implicated in the etiology of rodent T-cell lymphoma (Staal et al. 1977). AKT has both proliferative and antiapoptotic effects whereas negatively regulating tumor suppressors including p53, GSK-3 $\beta$, and the forkheadbox family of transcription factors (FOXOs) (Liu et al. 2009). The proliferative effects of AKT are conveyed by antagonism of p53-mediated growth arrest and inhibition of CIP/KIP family cyclin/CDK inhibitors. AKT directly inhibits apoptosis by promoting the cytoplasmic sequestration of BAD (Datta et al. 2000) and downregulating the transcription of BIM (which is normally transactivated by FOXOs). AKT also stabilizes the levels of endogenous IAP proteins (Dan et al. 2004), whereas AKT-mediated phosphorylation of caspases can increase resistance to cleavage (Cardone et al. 1998).

The functional relationship between MYC, $\mathrm{AKT}$, and MTOR provides a further example of the duality of MYC and the potential for MYC 
Oncogenes in Cell Survival and Cell Death

to cooperate with other oncogenes (Fig. 2). MYC transcriptionally represses TSC-2 expression (Ravitz et al. 2007), the regulatory complex that bridges AKT and MTORC-1 in canonical PI3K signaling (Astrinidis and Henske 2005). TSC-2 downregulates MTORC- 1 but is required for full activation of the second rapamycin insensitive MTOR complex (MTORC-2) (Huang et al. 2008). As MTORC-2 cooperates with PI3K to activate AKT, the net effect of MYC expression is to promote MTORC-1 while suppressing MTORC-2/AKT. This "binary switch" protects against the oncogenic effects of MTORC-1 activation by dampening upstream AKT phosphorylation. Interestingly, chronic pharmacological MTORC-1 antagonism can prevent the onset of lymphoma in experimental Myc-driven lymphoma. Conversely genetic activation of AKT by myristoylation (similar to vAKT) dramatically accelerates $M y c$-driven transformation, putatively by counteracting the normally suppressive effects of MYC on MTORC-2/AKT (Wendel et al. 2004).

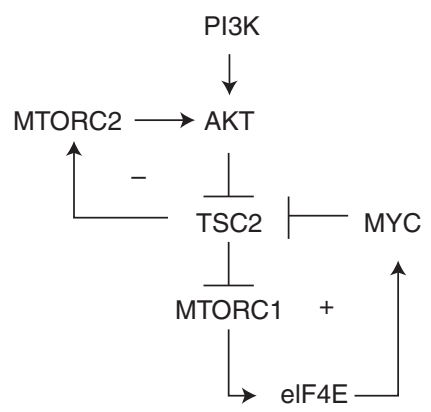

Figure 2. The interplay between MYC AND PI3K/ MTOR. The MYC-regulated transcriptional network interacts with canonical PI3K/AKT/MTOR signaling at multiple levels with opposing "counter-regulatory effects." In one example, $M Y C$ represses the activity of TSC to activate MTORC- 1 and enhance the cell's capacity to translate $M Y C$-mRNA in what is postulated to represent an oncogenic feed-forward loop $(+)$. The concurrent regulatory "fail-safe" is that TSC is required for full activation of the AKT hydrophobic motif-kinase, MTORC-2. In this way, MYC activates MTORC-1 while dampening MTORC-2/AKT activity $(-)$. Consequently, oncogenic activation of AKT by MTORC-2 independent mechanisms dramatically accelerates $M Y C$-driven oncogenesis.

\section{ONCOGENIC RAS}

The RAS proto-oncogenes (HRAS, NRAS, KRAS) encode small monomeric GTPases. Wild-type RAS proteins are conformationally activated when bound to GTP and become inactive by the process of hydrolyzing GTP to GDP. Oncogenic RAS is resistant to GAPs, locking the protein into its GTP-bound active conformation. Activating mutations in RAS genes occur in $>30 \%$ of all tumors (Fernandez-Medarde and Santos 2011). GTP-bound RAS binds and activates a range of effector proteins, most notably PI3K (p110) and RAF (Castellano and Downward 2010). Mutant RAS and PIK3CA have the potential to cooperate in PI3K pathway activation and colorectal tumors with genetic lesions in both the RAS/RAF/MEK/ERK and PI3K pathways have been reported (Yuan and Cantley 2008). In contrast, mutations of $R A S$ and $R A F$ are thought to be mutually exclusive in human cancer, suggesting functional redundancy (Sensi et al.2006). RAF is a Ser/Thr kinase that initiates a phosphorylation cascade including MEK and MAPK. Oncogenic RAF mutations are implicated in the pathogenesis of melanoma and colorectal cancer (Davies et al. 2002). Engagement of the PI3K/AKT is a major mechanism of RAS-mediated inhibition of apoptosis (Castellano and Downward 2010). In addition, various downstream effectors including TBK1, AKT, and Rac can facilitate RAS-induced activation of NF$\kappa \mathrm{B}$ signaling to suppress apoptosis that may be p53-dependent and-independent depending on the cellular context (Mayo et al. 1997; Cox and Der 2003; Barbie et al. 2009; Meylan et al. 2009). Through multiple molecular mechanisms, RAS concomitantly enhances cellular proliferation and inhibits apoptosis (Castellano and Downward 2010). However, cooperating genetic lesions are required for RAS-induced transformation, indicating the presence of intrinsic fail-safe mechanisms to suppress tumorigenesis. In the case of RAS, induction of senescence may play a protective role against its combined oncogenic proliferative and antiapoptotic effects in vivo. Whereas ectopic expression of RAS in normal cells promotes a senescent phenotype, this is dependent to a varying extent of intact p53/DDR 
detection mechanisms (Serrano et al. 1997). Hence, loss of DDR-related tumor suppressors is one cooperative mechanism by which RASinduced senescence may be overcome in transformation.

\section{INDUCTION OF APOPTOSIS THROUGH TARGETING ONCOGENES}

If suppression of apoptosis is key for oncoproteins to mediate their tumorigenic effects then one would predict that targeted inhibition of the transforming oncoprotein, or of the cooperating protein that suppresses oncogene-induced apoptosis, would result in a robust proapoptotic response. This is indeed the case when the Ablkinase inhibitor, imatinib, is used against $B C R$ $A B L$-addicted cells (O'Dwyer and Druker 2000), when the EGFR inhibitor, gefitinib, is used to treat tumors addicted to activated EGFR (Takeuchi and Ito 2010), and when the PI3K/AKT pathway is targeted using MTOR inhibitors in the context of constitutive AKT activation (Wendel et al. 2004). At present, direct pharmacological inhibitors of RAS and MYC have not yet been developed. However, transgenic mouse models of inducible $M y c$ - or Ras-induced oncogenesis, showed dramatic apoptosis and subsequent tumor regression when these proteins were "turned off” (Chin et al. 1999; Felsher and Bishop 1999; Jain et al. 2002) indicating that this would be an effective cancer therapy strategy should these proteins or key downstream effectors be targeted. Moreover, we and others have shown that $M y c$-driven tumors that coexpress BCL2 or BCLXL resulting in accelerated tumorigenesis are highly sensitive to apoptosis ABT737 , the small molecule inhibitor of BCL2 and BCLXL, resulting in an effective therapeutic response (Mason et al. 2008; Whitecross et al. 2009). This provides proof-of-principle that targeting a second, cooperating apoptotic lesion may be effective against tumors that are addicted to a different "driver" oncogene.

\section{CONCLUDING REMARKS}

It is well recognized that two important cooperating hallmarks of tumorigenesis are unre- strained cell proliferation and resistance to apoptosis. Whereas certain proto-oncogenes such as $B C R-A B L$ may be capable of concomitantly inducing both of these important effects, others such as MYC must circumvent intrinsic failsafe mechanisms that have evolved to counter unrestrained cell proliferation. Accordingly, genetic lesions that cooperate with MYC to facilitate cellular transformation are most often those that inactivate regulatory proapoptotic pathways such as the ARF/MDM2/p53 axis. Understanding the molecular interplay between genes and signaling pathways that cooperate to drive cell proliferation and inhibit apoptosis have provided important mechanistic insight into the complex process of cellular transformation. Importantly however, such scientific detail has provided the impetus to develop novel therapeutic agents that target the "apoptotic arm" of a driver or cooperating oncogene. Accordingly, successful treatment of an "oncogene-addicted" tumor may not necessarily require direct inhibition of the proto-oncogene itself, but may be achieved through inactivation of the cooperating antiapoptotic countermeasure that is by definition essential for survival of the neoplastic cell.

\section{ACKNOWLEDGMENTS}

R.W.J. is a principal research fellow of the $\mathrm{Na}$ tional Health and Medical Research Council of Australia (NHMRC) and is supported by NHMRC Program and Project Grants, the Susan G. Komen Breast Cancer Foundation, the Prostate Cancer Foundation of Australia, Cancer Council Victoria, the Victorian Cancer Agency, the Leukemia Foundation of Australia, Victorian Breast Cancer Research Consortium, and the Australian Rotary Health Foundation. J.S. is supported by the Leukaemia Foundation of Australia and the Cooperative Research Centre for Biomedical Imaging Development.

\section{REFERENCES}

Adhikary S, Eilers M. 2005. Transcriptional regulation and transformation by Myc proteins. Nat Rev Mol Cell Biol 6: 635-645. 
Astrinidis A, Henske EP. 2005. Tuberous sclerosis complex: Linking growth and energy signaling pathways with human disease. Oncogene 24: 7475-7481.

Aukema SM, Siebert R, Schuuring E, van Imhoff GW, Kluin-Nelemans HC, Boerma EJ, Kluin PM. 2011. Double-hit B-cell lymphomas. Blood 117: 2319-2331.

Barbie DA, Tamayo P, Boehm JS, Kim SY, Moody SE, Dunn IF, Schinzel AC, Sandy P, Meylan E, Scholl C, et al. 2009. Systematic RNA interference reveals that oncogenic KRAS-driven cancers require TBK1. Nature 462: $108-112$.

Beverly LJ, Varmus HE. 2009. MYC-induced myeloid leukemogenesis is accelerated by all six members of the antiapoptotic BCL family. Oncogene 28: 1274-1279.

Bouchard C, Dittrich O, Kiermaier A, Dohmann K, Menkel A, Eilers M, Luscher B. 2001. Regulation of cyclin D2 gene expression by the Myc/Max/Mad network: Myc-dependent TRRAP recruitment and histone acetylation at the cyclin D2 promoter. Genes Dev 15: $2042-$ 2047.

Campbell KJ, Bath ML, Turner ML, Vandenberg CJ, Bouillet P, Metcalf D, Scott CL, Cory S. 2010. Elevated Mcl-1 perturbs lymphopoiesis, promotes transformation of hematopoietic stem/progenitor cells, and enhances drug resistance. Blood 116: 3197-3207.

Cardone MH, Roy N, Stennicke HR, Salvesen GS, Franke TF, Stanbridge E, Frisch S, Reed JC. Regulation of cell death protease caspase-9 by phosphorylation. Science 282: $1318-1321$.

Castellano E, Downward J. 2010. RAS interaction with PI3K More than just another effector pathway. Genes Cancer 2: 261-274.

Chin L, Tam A, Pomerantz J, Wong M, Holash J, Bardeesy N, Shen Q, O’Hagan R, Pantginis J, Zhou H, et al. 1999. Essential role for oncogenic Ras in tumour maintenance. Nature 400: 468-472.

Cox AD, Der CJ. 2003. The dark side of Ras: Regulation of apoptosis. Oncogene 22: 8999-9006.

Dan HC, Sun M, Kaneko S, Feldman RI, Nicosia SV, Wang HG, Tsang BK, Cheng JQ. 2004. Akt phosphorylation and stabilization of X-linked inhibitor of apoptosis protein (XIAP). J Biol Chem 279: 5405-5412.

Datta SR, Katsov A, Hu L, Petros A, Fesik SW, Yaffe MB, Greenberg ME. 2000. 14-3-3 proteins and survival kinases cooperate to inactivate BAD by BH3 domain phosphorylation. Mol Cell 6: 41-51.

Davies H, Bignell GR, Cox C, Stephens P, Edkins S, Clegg S, Teague J, Woffendin H, Garnett MJ, Bottomley W, et al. 2002. Mutations of the BRAF gene in human cancer. Nature 417: 949-954.

Druker BJ. 2008. Translation of the Philadelphia chromosome into therapy for CML. Blood 112: 4808-4817.

Egle A, Harris AW, Bouillet P, Cory S. 2004. Bim is a suppressor of Myc-induced mouse B cell leukemia. Proc Natl Acad Sci 101: 6164-6169.

Eischen CM, Weber JD, Roussel MF, Sherr CJ, Cleveland JL. 1999. Disruption of the ARF-Mdm2-p53 tumor suppressor pathway in Myc-induced lymphomagenesis. Genes Dev 13: 2658-2669.
Engelman JA. 2009. Targeting PI3K signalling in cancer: Opportunities, challenges and limitations. Nat Rev Cancer 9: 550-562.

Engelman JA, Luo J, Cantley LC. 2006. The evolution of phosphatidylinositol 3-kinases as regulators of growth and metabolism. Nat Rev Genet 7: 606-619.

Evan GI, Wyllie AH, Gilbert CS, Littlewood TD, Land H, Brooks M, Waters CM, Penn LZ, Hancock DC. 1992. Induction of apoptosis in fibroblasts by c-myc protein. Cell 69: 119-128.

Faber AC, Li D, Song Y, Liang MC, Yeap BY, Bronson RT, Lifshits E, Chen Z, Maira SM, Garcia-Echeverria C, et al. 2009. Differential induction of apoptosis in HER2 and EGFR addicted cancers following PI3K inhibition. Proc Natl Acad Sci 106: 19503-19508.

Felsher DW, Bishop JM. 1999. Reversible tumorigenesis by MYC in hematopoietic lineages. Mol Cell 4 199-207.

Fernandez-Medarde A, Santos E. 2011. Ras in cancer and developmental diseases. Genes Cancer 2: 344-358.

Gomez-Roman N, Felton-Edkins ZA, Kenneth NS, Goodfellow SJ, Athineos D, Zhang J, Ramsbottom BA, Innes F, Kantidakis T, Kerr ER, et al. 2006. Activation by c-Myc of transcription by RNA polymerases I, II and III. Biochem Soc Symp 141-154.

Gustafson WC, Weiss WA. 2010. Myc proteins as therapeutic targets. Oncogene 29: 1249-1259.

Hanahan D, Weinberg RA. 2000. The hallmarks of cancer. Cell 100: $57-70$.

Hanahan D, Weinberg RA. 2011. Hallmarks of cancer: The next generation. Cell 144: 646-674.

Hemann MT, Zilfou JT, Zhao Z, Burgess DJ, Hannon GJ, Lowe SW. 2004. Suppression of tumorigenesis by the p53 target PUMA. Proc Natl Acad Sci 101: 9333-9338.

Hermeking H, Rago C, Schuhmacher M, Li Q, Barrett JF, Obaya AJ, O'Connell BC, Mateyak MK, Tam W, Kohlhuber F, et al. 2000. Identification of CDK4 as a target of c-MYC. Proc Natl Acad Sci 97: 2229-2234.

Huang J, Dibble CC, Matsuzaki M, Manning BD. 2008. The TSC1-TSC2 complex is required for proper activation of mTOR complex 2. Mol Cell Biol 28: 4104-4115.

Jain M, Arvanitis C, Chu K, Dewey W, Leonhardt E, Trinh M, Sundberg CD, Bishop JM, Felsher DW. 2002. Sustained loss of a neoplastic phenotype by brief inactivation of MYC. Science 297: 102-104.

Kharas MG, Janes MR, Scarfone VM, Lilly MB, Knight ZA, Shokat KM, Fruman DA. 2008. Ablation of PI3K blocks BCR-ABL leukemogenesis in mice, and a dual PI3K/ mTOR inhibitor prevents expansion of human BCR$\mathrm{ABL}^{+}$leukemia cells. J Clin Invest 118: 3038-3050.

Kinzler KW, Vogelstein B. 1996. Lessons from hereditary colorectal cancer. Cell 87: 159-170.

Kinzler KW, Vogelstein B. 1998. Landscaping the cancer terrain. Science 280: 1036-1037.

Koptyra M, Cramer K, Slupianek A, Richardson C, Skorski T. 2008. BCR/ABL promotes accumulation of chromosomal aberrations induced by oxidative and genotoxic stress. Leukemia 22: 1969-1972.

Kuppers R, Dalla-Favera R. 2001. Mechanisms of chromosomal translocations in B cell lymphomas. Oncogene 20: 5580-5594. 
Lee S, Chari NS, Kim HW, Wang X, Roop DR, Cho SH, DiGiovanni J, McDonnell TJ. 2007. Cooperation of Haras and Bcl-2 during multistep skin carcinogenesis. Mol Carcinog 46: 949-957.

Lin CJ, Malina A, Pelletier J. 2009. c-Myc and eIF4F constitute a feedforward loop that regulates cell growth: Implications for anticancer therapy. Cancer Res 69: 7491-7494.

Liu P, Cheng H, Roberts TM, Zhao JJ. 2009. Targeting the phosphoinositide 3-kinase pathway in cancer. Nat Rev Drug Discov 8: 627-644.

Lowe SW, Cepero E, Evan G. 2004. Intrinsic tumour suppression. Nature 432: 307-315.

Marmor MD, Skaria KB, Yarden Y. 2004. Signal transduction and oncogenesis by ErbB/HER receptors. Int $J \mathrm{Ra}$ diat Oncol Biol Phys 58: 903-913.

Mason KD, Vandenberg CJ, Scott CL, Wei AH, Cory S, Huang DC, Roberts AW. 2008. In vivo efficacy of the Bcl-2 antagonist ABT-737 against aggressive Myc-driven lymphomas. Proc Natl Acad Sci 105: 17961-17966.

Mayo MW, Wang CY, Cogswell PC, Rogers-Graham KS, Lowe SW, Der CJ, Baldwin AS Jr. 1997. Requirement of NF- $\kappa \mathrm{B}$ activation to suppress p53-independent apoptosis induced by oncogenic Ras. Science 278: 1812-1815.

Meyer N, Penn LZ. 2008. Reflecting on 25 years with MYC Nat Rev Cancer 8: 976-990.

Meylan E, Dooley AL, Feldser DM, Shen L, Turk E, Ouyang C, Jacks T. 2009. Requirement for NF- $\kappa B$ signalling in a mouse model of lung adenocarcinoma. Nature 462: 104-107.

Michalak EM, Jansen ES, Happo L, Cragg MS, Tai L, Smyth GK, Strasser A, Adams JM, Scott CL. 2009. Puma and to a lesser extent Noxa are suppressors of Myc-induced lymphomagenesis. Cell Death Differ 16: 684-696.

Nowicki MO, Falinski R, Koptyra M, Slupianek A, Stoklosa T, Gloc E, Nieborowska-Skorska M, Blasiak J, Skorski T. 2004. BCR/ABL oncogenic kinase promotes unfaithful repair of the reactive oxygen species-dependent DNA double-strand breaks. Blood 104: 3746-3753.

O’Dwyer ME, Druker BJ. 2000. STI571: An inhibitor of the BCR-ABL tyrosine kinase for the treatment of chronic myelogenous leukaemia. Lancet Oncol 1: 207-211.

Oswald F, Lovec H, Moroy T, Lipp M. 1994. E2F-dependent regulation of human MYC: Trans-activation by cyclins D1 and A overrides tumour suppressor protein functions. Oncogene 9: 2029-2036.

Perrotti D, Jamieson C, Goldman J, Skorski T. 2010. Chronic myeloid leukemia: Mechanisms of blastic transformation. J Clin Invest 120: 2254-2264.

Ravitz MJ, Chen L, Lynch M, Schmidt EV. 2007. c-myc repression of TSC2 contributes to control of translation initiation and Myc-induced transformation. Cancer Res 67: 11209-11217.

Reimann M, Loddenkemper C, Rudolph C, Schildhauer I, Teichmann B, Stein H, Schlegelberger B, Dorken B, Schmitt CA. 2007. The Myc-evoked DNA damage response accounts for treatment resistance in primary lymphomas in vivo. Blood 110: 2996-3004.

Schmelzle T, Hall MN. 2000. TOR, a central controller of cell growth. Cell 103: 253-262.
Schmitt CA, McCurrach ME, de Stanchina E, WallaceBrodeur RR, Lowe SW. 1999. INK4a/ARF mutations accelerate lymphomagenesis and promote chemoresistance by disabling p53. Genes Dev 13: 2670-2677.

Schmitt CA, Fridman JS, Yang M, Baranov E, Hoffman RM, Lowe SW. 2002. Dissecting p53 tumor suppressor functions in vivo. Cancer Cell 1: 289-298.

Sears RC. 2004. The life cycle of C-myc: From synthesis to degradation. Cell Cycle 3: 1133-1137.

Sensi M, Nicolini G, Petti C, Bersani I, Lozupone F, Molla A, Vegetti C, Nonaka D, Mortarini R, Parmiani G, et al. 2006. Mutually exclusive NRASQ61R and BRAFV600E mutations at the single-cell level in the same human melanoma. Oncogene 25: 3357-3364.

Seoane J, Le HV, Massague J. 2002. Myc suppression of the p21(Cip1) Cdk inhibitor influences the outcome of the p53 response to DNA damage. Nature 419: 729-734.

Serrano M, Lin AW, McCurrach ME, Beach D, Lowe SW. 1997. Oncogenic ras provokes premature cell senescence associated with accumulation of p53 and p16INK4a. Cell 88: $593-602$.

Staal SP, Hartley JW, Rowe WP. 1977. Isolation of transforming murine leukemia viruses from mice with a high incidence of spontaneous lymphoma. Proc Natl Acad Sci 74: 3065-3067.

Strasser A, Harris AW, Bath ML, Cory S. 1990. Novel primitive lymphoid tumours induced in transgenic mice by cooperation between myc and bcl-2. Nature 348: $331-333$.

Takeuchi K, Ito F. 2010. EGF receptor in relation to tumor development: Molecular basis of responsiveness of cancer cells to EGFR-targeting tyrosine kinase inhibitors. FEBS J 277: $316-326$.

Vafa O, Wade M, Kern S, Beeche M, Pandita TK, Hampton GM, Wahl GM. 2002. c-Myc can include DNA damage, increase reactive oxygen species, and mitigate p53 function: A mechanism for oncogene-induced genetic instability. Mol Cell 9: 1031-1044.

Vita M, Henriksson M. 2006. The Myc oncoprotein as a therapeutic target for human cancer. Semin Cancer Biol 16: $318-330$.

Vivanco I, Sawyers CL. 2002. The phosphatidylinositol 3kinase AKT pathway in human cancer. Nat Rev Cancer 2 489-501.

Weinstein IB. 2002. Cancer. Addiction to oncogenes-The Achilles heal of cancer. Science 297: 63-64.

Wendel HG, De Stanchina E, Fridman JS, Malina A, Ray S, Kogan S, Cordon-Cardo C, Pelletier J, Lowe SW. 2004. Survival signalling by Akt and eIF4E in oncogenesis and cancer therapy. Nature 428: 332-337.

Wheeler DL, Dunn EF, Harari PM. 2010. Understanding resistance to EGFR inhibitors-impact on future treatment strategies. Nat Rev Clin Oncol 7: 493-507.

Whitecross KF, Alsop AE, Cluse LA, Wiegmans A, Banks KM, Coomans C, Peart MJ, Newbold A, Lindemann RK, Johnstone RW. 2009. Defining the target specificity of ABT-737 and synergistic antitumor activities in combination with histone deacetylase inhibitors. Blood 113: 1982-1991.

Yuan TL, Cantley LC. 2008. PI3K pathway alterations in cancer: Variations on a theme. Oncogene 27: 5497-5510. 


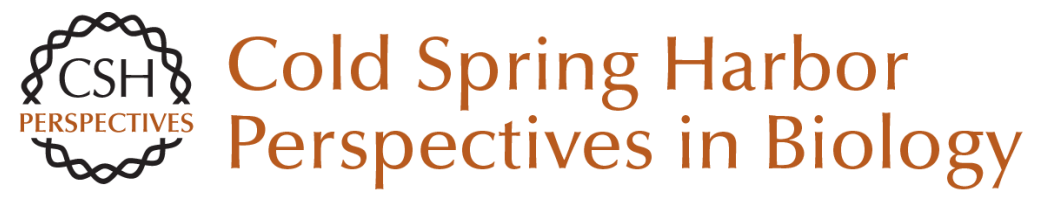

\section{Oncogenes in Cell Survival and Cell Death}

Jake Shortt and Ricky W. Johnstone

Cold Spring Harb Perspect Biol 2012; doi: 10.1101/cshperspect.a009829

Subject Collection Cell Survival and Cell Death

Programmed Cell Death in the Evolutionary Race against Bacterial Virulence Factors

Carolyn A. Lacey and Edward A. Miao

The Evolutionary Origins of Programmed Cell

Death Signaling

Kay Hofmann

Regulation of Cell Death and Immunity by XIAP Philipp J. Jost and Domagoj Vucic

Dysregulation of Cell Death in Human Chronic Inflammation

Yue Li, Christoph Klein and Daniel Kotlarz

Cell Death in Plant Immunity

Eugenia Pitsili, Ujjal J. Phukan and Nuria S. Coll

Recent Insights on Inflammasomes, Gasdermin Pores, and Pyroptosis

Nathalia M. de Vasconcelos and Mohamed Lamkanfi

Phagocyte Responses to Cell Death in Flies Andrew J. Davidson and Will Wood

Mechanism and Regulation of

Gasdermin-Mediated Cell Death

Shiyu Xia, Louis Robert Hollingsworth IV and Hao Wu

For additional articles in this collection, see http://cshperspectives.cshlp.org/cgi/collection/

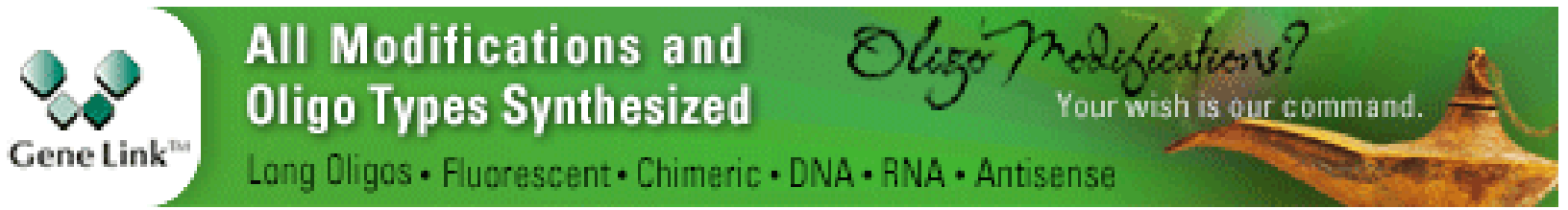

Cell Death and Neurodegeneration Benjamin J. Andreone, Martin Larhammar and Joseph W. Lewcock

Death Receptors and Their Ligands in Inflammatory Disease and Cancer Alessandro Annibaldi and Henning Walczak

The Killer Pseudokinase Mixed Lineage Kinase Domain-Like Protein (MLKL) James M. Murphy

Neutrophil Extracellular Traps in Host Defense Sabrina Sofia Burgener and Kate Schroder

Cell-Cycle Cross Talk with Caspases and Their Substrates Patrick Connolly, Irmina Garcia-Carpio and Andreas Villunger

Cracking the Cell Death Code Carla V. Rothlin and Sourav Ghosh

BAX, BAK, and BOK: A Coming of Age for the BCL-2 Family Effector Proteins

Tudor Moldoveanu and Peter E. Czabotar

Multitasking Kinase RIPK1 Regulates Cell Death and Inflammation

Kim Newton

Copyright @ 2012 Cold Spring Harbor Laboratory Press; all rights reserved 
For additional articles in this collection, see http://cshperspectives.cshlp.org/cgi/collection/

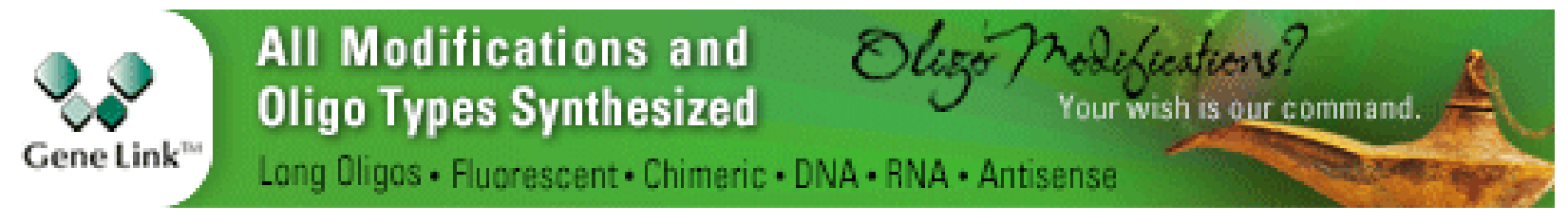

Copyright @ 2012 Cold Spring Harbor Laboratory Press; all rights reserved 